\title{
Dendrobeaniamine A, a New Alkaloid from the Arctic Marine
}

\section{Bryozoan Dendrobeania murrayana}

Priyanka Michael ${ }^{1}$, Espen Hansen ${ }^{1}$, Johan Isaksson ${ }^{2}$, Jeanette H. Andersen ${ }^{1}$ and Kine Ø. Hansen ${ }^{1, *}$

${ }^{I}$ Marbio, UiT-The Arctic University of Norway, Breivika, Troms $\phi$ N-9037, Norway

${ }^{2}$ Department of Chemistry, UiT-The Arctic University of Norway, Breivika, Troms $\phi$ N9037, Norway

*corresponding author

E-mail: Kine.o.hanssen@uit.no 


\title{
Dendrobeaniamine A, a New Alkaloid from the Arctic Marine Bryozoan Dendrobeania murrayana
}

\author{
Abstract: The new guanidine alkaloid Dendrobeaniamine A (1) was isolated \\ from the organic extract of the Arctic marine bryozoan Dendrobeania \\ murrayana. The chemical structure of $\mathbf{1}$ was elucidated by spectroscopic \\ experiments, including 1D and 2D NMR and HRESIMS analysis. Compound $\mathbf{1}$ is \\ a lipoamino acid, consisting of a $\mathrm{C}_{12}$ fatty acid anchored to the amino acid \\ arginine. The bioactivity of $\mathbf{1}$ was evaluated using cellular and biochemical \\ assays, but the compound did not show cytotoxic, antimicrobial, anti- \\ inflammatory or antioxidant activities
}

Keywords: Arctic invertebrates; bryozoans; Dendrobeania murrayana; bioprospecting, marine secondary metabolites.

\section{Introduction}

Bryozoans are filter feeding, sessile invertebrates from which structurally diverse bioactive secondary metabolites have been isolated (Ryland 2005; Maltseva et al. 2017; Tian et al. 2018). Despite this, the number of investigations into the natural product chemistry of marine bryozoans is still limited compared to other marine invertebrate phyla. To date, only around 220 secondary metabolites have been isolated from 38 species of marine bryozoans (Blunt et al. 2018). These natural products include the flustramines (Peters et al. 2002), the eusynstyelamides (Tadesse et al. 2011), the bryostatins (Kollár et al. 2014) and the securamines (Hansen et al. 2017).

As a part of our ongoing search for new secondary metabolites from Arctic invertebrates (Svenson 2013; Michael et al. 2017; Hansen et al. 2018), we are reporting a new secondary metabolite from the Arctic marine bryozoan Dendrobeania murrayana, from which the tetracyclic terpenoid murrayanolide have been previously isolated (Yu and Wright 1995). A detailed chemical analysis of the organic extract of $D$. 
murrayana using UHPLC-HRESIMS revealed the presence of an abundant compound not present in other bryozoan extracts analyzed by our research group. The compound was isolated and its structure elucidated using 1D and 2D NMR and HRESIMS analysis. Potential biological activities of the isolated compound was evaluated using cellular and biochemical assays.

\section{Results and discussion}

\subsection{Extraction, dereplication and isolation of 1}

Specimens of Dendrobeania murrayana (550 g wet weight) were collected in the subtidal region of Vesterålsfjorden in Northern Norway and prepared into an organic extract (1.59 g). An aliquot of the organic extract was analyzed by UHPLC-HRESIMS. Comparison of base peak intensity (BPI) chromatograms of the organic extract from $D$. murrayana with other related bryozoans revealed the presence of a unique and prominent peak at $R_{\mathrm{t}} 5.7$ min with an $\mathrm{m} / z$ of 369.2861 and a calculated elemental composition of $\mathrm{C}_{19} \mathrm{H}_{36} \mathrm{~N}_{4} \mathrm{O}_{3}$. The elemental composition gave no hits when searched for in relevant databases (Dictionary of Marine Natural Products and ChemSpider). Based on the prominence of this peak (Figure S1) and its assumed novelty based on the database searches, we decided to isolate the compound and determine its structure.

We isolated the compound from the organic extract using mass guided semi-preparative HPLC fractionation. In order to obtain sufficient purity of the compound, it was purified in two steps; first by applying a $\mathrm{C}_{18}$ column followed by a second step using a fluorophenyl column, both with gradients of water and acetonitrile as mobile phases. The isolation gave $2.5 \mathrm{mg}$ of pure compound $\mathbf{1}$. 


\subsection{Structure elucidation of 1}

Compound 1 was obtained as a golden yellow wax. The protonated compound had a $\mathrm{m} / \mathrm{z}$ of 369.2861 , and the elemental composition was $\mathrm{C}_{19} \mathrm{H}_{36} \mathrm{~N}_{4} \mathrm{O}_{3}$. The IR spectrum of compound 1 had characteristic signals at 3279, 2936, 2363, 1726, 1626, $1544 \mathrm{~cm}^{-1}$, indicating the presence of amine, alkane, alcohol, carbonyl, alkene and imine groups, respectively. The UV $\lambda_{\max }$ of compound 1 was $223 \mathrm{~nm}$. Through a set of $1 \mathrm{D}\left({ }^{1} \mathrm{H},{ }^{13} \mathrm{C}\right)$ and $2 \mathrm{D}\left({ }^{1} \mathrm{H},{ }^{13} \mathrm{C},{ }^{15} \mathrm{~N}\right)\left(\mathrm{HSQC}, \mathrm{HMBC}, \mathrm{COSY}\right.$, NOESY, TOCSY, H2BC, ${ }^{15} \mathrm{~N}-\mathrm{HSQC}$ and ${ }^{15} \mathrm{~N}-\mathrm{HMBC}$ ) NMR experiments, the structure of $\mathbf{1}$ could be determined (Figure 1, Table S1, Figures S2 and S4-S16).

Initially, only 17 out of the 19 carbons could be identified in the 1D carbon spectrum, the missing carbons were later to be assigned C-15 $\left(\delta_{C} 55.0\right)$ and $C-16\left(\delta_{C} 169.6\right) . C-15$ was absent in HSQC, but could be identified in a (145 Hz) HMQC. Very weak peaks could eventually be confirmed in an optimized 1D carbon and HMBC. A fine splitting could be observed for carbon peaks belonging to C-10 ( $\left.\delta_{\mathrm{C}} 155.9\right), \mathrm{C}-12\left(\delta_{\mathrm{C}} 119.8\right), \mathrm{C}-$ $13\left(\delta_{\mathrm{C}} 168.7\right)$ and $\mathrm{C}-17\left(\delta_{\mathrm{C}} 31.2\right)$. This indicates that there is a dynamic process, presumably C-15/C-16 rotamers. Comparison to the edited HSQC concluded the carbons to be in total $2 \mathrm{CH}_{3}, 11 \mathrm{CH}_{2}, 2 \mathrm{CH}$ and 4 quaternary carbons. Of these, two had chemical shifts characteristic for carbonyls. The COSY and TOCSY data revealed one spin system consisting of H-14 $\left(\delta_{\mathrm{H}} 7.40\right), \mathrm{H}-15\left(\delta_{\mathrm{H}} 4.32\right), \mathrm{H}-17 \mathrm{a}\left(\delta_{\mathrm{H}} 1.87\right), \mathrm{H}-17 \mathrm{~b}\left(\delta_{\mathrm{H}}\right.$ $1.72), \mathrm{H}_{2}-18\left(\delta_{\mathrm{H}} 1.63\right)$ and $\mathrm{H}_{2}-19\left(\delta_{\mathrm{H}} 3.21\right), \mathrm{H}-20\left(\delta_{\mathrm{H}} 7.55\right)$, and a second spin system consisting of an aliphatic chain $\mathrm{H}_{3}-1\left(\delta_{\mathrm{H}} 0.89\right)$ to $\mathrm{H}_{2}-9\left(\delta_{\mathrm{H}} 2.60\right)$. Arrangements of the aliphatic chain with respect to the other spin system and the connecting moiety were determined by HMBC, H2BC and COSY correlations (Figure S6-S8). The C-11 ( $\delta_{\mathrm{C}}$ 24.8) methyl was attached to the quaternary $\mathrm{C}-10\left(\delta_{\mathrm{C}} 155.9\right)$, based on HMBC correlations between $\mathrm{H}_{3}-11$ and $\mathrm{C}-9\left(\delta_{\mathrm{C}} 33.9\right), \mathrm{C}-10$ and $\mathrm{C}-12\left(\delta_{\mathrm{C}} 119.8\right)$ as well as 
between $\mathrm{C}-11$ and $\mathrm{H}_{2}-9$ and $\mathrm{H}-12$. The aliphatic chain was thus connected to $\mathrm{C}-10 . \mathrm{C}-13$ $\left(\delta_{\mathrm{C}} 168.7\right)$ was identified as a carbonyl next to the aromatic $\mathrm{C}-12$, again based on the HMBC pattern, including correlations from $\mathrm{HN}-14\left(\delta_{\mathrm{H}} 7.40\right)$ and $\mathrm{H}-12\left(\delta_{\mathrm{H}} 5.74\right)$.

The other spin system presented some difficulty because of the putative C-15/C-16 rotamers, resulting in the absence of long range through bonds correlations involving these carbons. The spin system itself was identified as the observable part of an arginine, and the side chain could be traced from the $\mathrm{NH}(\mathrm{HN}-14)$ to the alpha- $(\mathrm{C}-15)$, beta- (C-17), gamma- (C-18) and delta carbon (C-19) and the epsilon NH (HN-20). The only experimental observation connecting it to the rest of the molecule was the ${ }^{3} J_{\mathrm{C} 13 \mathrm{H} 14}$ (Figure S6), supported by a NOE from H-14 to H-12 (Figure S10). In the H2BC spectrum, a coupling between $\mathrm{H}-20\left(\delta_{\mathrm{H}} 7.55\right)$ and $\mathrm{C}-19\left(\delta_{\mathrm{C}} 42.2\right)$ conformed the attachment of an NH to C-19. Furthermore, HMBC correlations between $\mathrm{H}_{2}-19\left(\delta_{\mathrm{H}}\right.$ 3.21) and C-21 $\left(\delta_{C} 158.7\right)$ linked the quaternary C-21 carbon atom to $\mathrm{N}-20\left(\delta_{\mathrm{N}} 84.1\right)$. This placeed the remaining $\mathrm{N}_{2} \mathrm{H}_{3}$ atoms to C-21, forming a guanidine group. In order to strengthen that the arginine spin system is actually connected to the rest of the molecule via the $\mathrm{N}$-terminal side and not via the $\mathrm{C}$-terminal side, the nitrogen chemical shifts were extracted from a ${ }^{15} \mathrm{~N}-\mathrm{HSQC}$ (Figure S13); $\delta_{\mathrm{N} 20} 84.1$ and $\delta_{\mathrm{N} 14} 127.7$ PPM. The nitrogen shifts were consistent with $\mathbf{1}$, but not with other potential structures (Figure S15 and S16). A weak ${ }^{15} \mathrm{~N}-\mathrm{HMBC}$ between $\mathrm{N}-20\left(\delta_{\mathrm{N}} 84.1\right)$ and $\mathrm{H}_{2}-18\left(\delta_{\mathrm{H}} 1.63\right)$ could be detected (Figure S14).

The configuration around the C-10/C-12 double bond was determined considering the size of the ${ }^{3} J_{\mathrm{C} 11 \mathrm{H} 12}$ and ${ }^{3} J_{\mathrm{C} 9 \mathrm{H} 12}$ couplings as estimated by CLIP-selHSQMBC and a selective SJS-scaled BIRD experiment (Figure S11 and S12). In both measurements, the ${ }^{3} J_{\mathrm{C} 9 \mathrm{H} 12}$ coupling was larger than the ${ }^{3} J_{\mathrm{C} 11 \mathrm{H} 12}$ coupling, which is consistent with a Zconfiguration of the double bond (i.e. the proton and the methyl in cis). This was 
confirmed by a clear NOE between $\mathrm{H}-12\left(\delta_{\mathrm{H}} 5.74\right)$ and $\mathrm{H}_{3}-11\left(\delta_{\mathrm{H}} 1.84\right)$.

\subsection{Evaluation of the bioactivity of 1}

Compound $\mathbf{1}$ is structurally related to the synthetically produced and commercially available antimicrobial compound lauric arginate (2) (Ma et al. 2013) as well as the cytotoxic natural product spermidine 1 (3) (Schmitz et al. 1979) isolated from the soft coral Sinularia brongersmai (Figure S3). Compound $\mathbf{2}$ is active against both gram positive and gram negative bacteria, and against biofilm formation. Compound $\mathbf{3}$ is active against various cancer cell lines found in the National Cancer Institute 60-cell line panel at sub- $\mu \mathrm{M}$ concentrations.

Amphipathic structures, consisting of a lipophilic chain and a charged region often act as surface-active molecules on biological membranes (Schreier et al. 2000; Schmidt and Wong 2013). Because of the structural features of $\mathbf{1}$ and its similarity to $\mathbf{2}$ and $\mathbf{3}$, the compound was tested for activity in a variety of bioactivity assays. Compound $\mathbf{1}$ was assayed against the cancer cell line A2058 and the non-malignant human lung fibroblasts cell line MRC-5, but displayed no effect at $10 \mu \mathrm{M}$. When evaluated for antimicrobial activity, $\mathbf{1}$ showed no activity at the highest assayed concentration (135.68 $\mu \mathrm{M}$ ) against $S$. aureus, E. coli, P. aeruginosa, E. faecalis or S. agalactiae (gr.B) and $C$. albicans, nor against the ability of $S$. epidermis to form biofilm. Furthermore, 1 was evaluated for its ability to inhibit the release of the cytokine tumor necrosis factor (TNF $\alpha$ ) from the human acute leukemia monocyte cell line (THP-1) at $10 \mu \mathrm{M}$. Compound $\mathbf{1}$ did not show anti-inflammatory effect. Compound $\mathbf{1}$ was evaluated for its antioxidant effect at $135.68 \mu \mathrm{M} \mu \mathrm{g}$ using an oxygen radical absorbance capacity (ORAC) assay and no significant effect was observed. The bioactivities of the similar 
compounds $\mathbf{2}$ and $\mathbf{3}$ could thus not be found in $\mathbf{1}$.

All the tree compounds share a $\mathrm{C}_{12}$ fatty acid chain, where $\mathbf{1}$ and $\mathbf{2}$ have a double bond between $\mathrm{C}-10$ and $\mathrm{C}-12$, and thus are monounsaturated. However, the stereochemistry around the double bond is different as $\mathbf{1}$ has cis while $\mathbf{3}$ has trans configuration. The presence of a double bond in $\mathbf{1}$ and $\mathbf{3}$ makes these structures more rigid compared to $\mathbf{2}$, which has an unsaturated fatty acid chain. Both compounds $\mathbf{1}$ and $\mathbf{2}$ contains the cationic amino acid residue arginine, but in $\mathbf{2}$ the hydroxyl group is ethylated so it can not be deprotonated and thus is not negatively charged. The zwitterionic nature of $\mathbf{1}$ may result in ionic bond formation between the negatively charged hydroxyl oxygen and positively charged guanidine group, possibly preventing $\mathbf{1}$ from integrating with the negatively charged bacterial membranes. This may explain the lack of observed antibacterial activity of $\mathbf{1}$ despite its structural resemblance to $\mathbf{2}$. The spermidine part of $\mathbf{3}$ differ from the polar amino acid groups of $\mathbf{1}$ and $\mathbf{2}$, as it lacks the terminal guanidine group, which is positively charged under physiological $\mathrm{pH}$. Differences in observed bioactivities between $\mathbf{1}$ compared to $\mathbf{2}$ and $\mathbf{3}$ can thus be explained by presence and absence of specific substituents, differences in the overall three-dimensional structures of the compounds and possibly by an intramolecular ionic bond formation in $\mathbf{1}$.

Reporting of natural products, despite being inactive in the selected bioassays, adds to the knowledge of the chemical diversity of invertebrate derived molecules. As production of secondary metabolites is energy consuming, the natural function of $\mathbf{1}$ is most likely to provide a beneficial effect for the producing animal, by acting as a pathogen or predator repellant, in competition for space of to protect against abiotic stress factors (Figuerola et al. 2017). Thus, it is likely that the compound is bioactive, just not in the bioactivity assays available to us (Li and Lou 2018). Future screening of 1 in a wider selection of bioassays might reveal its biological function. 


\subsection{Dendrobeaniamine A (1)}

Golden yellow substance; $[\alpha]^{20}$ D -18.75 \pm 0.02 ( $\left.c 0.16 \mathrm{MeOH}\right) ; \mathrm{UV}=(\mathrm{ACN}) \lambda_{\max } 223$ $\mathrm{nm} ; \mathrm{IR} v \max 3279,2936,2363,1726,1626,1544, \mathrm{~cm}^{-1} \cdot{ }^{1} \mathrm{H}$ and ${ }^{13} \mathrm{C}$ NMR data (see Table S1); HRMS $m / z$ 369.2861 $[\mathrm{M}+\mathrm{H}]^{+}$(calculated for $\mathrm{C}_{19} \mathrm{H}_{37} \mathrm{~N}_{4} \mathrm{O}_{3}=369.2865$ ).

\section{Conclusion}

Chemistry guided purification of the organic extract of the Arctic marine bryozoan $D$. murrayana yielded one new compound, Dendrobeaniamine A (1). This compound was present in abundant amounts in the organic extract. We were not able to pinpoint the activity of this compound by the bioactivity assays available to us. The bioactivity and natural function of this compound thus remains to be elucidated.

Acknowledgements

The authors would like to thank Marbank for marine bryozoan collection, identification, and extraction. We also would like to acknowledge the department engineers Marte Albrigtsen and Kirsti Helland for the bioactivity experiments.

Supplemental materials

Supplementary data: Materials and methods, Table S1, Figures S1-S16: HRESIMS chromatogram of the organic D. murrayana extract, key 2D NMR correlation, structural comparison of $\mathbf{1}-\mathbf{3},{ }^{1} \mathrm{H},{ }^{13} \mathrm{C}$, HSQC+HMBC, H2BC, COSY, TOCSY, NOESY CLIPselHSQMBC and ${ }^{15} \mathrm{~N}$ NMR spectral data of isolated compound $\mathbf{1}$ associated with this article can be found online.

Disclosure statement

The authors declare no conflict of interest. 
References

Blunt JW, Carroll AR, Copp BR, Davis RA, Keyzers RA, Prinsep MR. 2018. Marine natural products. Nat Prod Rep. 35(1):8-53.

Figuerola B, Angulo-Preckler C, Nunez-Pons L, Moles J, Sala-Comorera L, GarciaAljaro C, Blanch AR, Avila C. 2017. Experimental evidence of chemical defence mechanisms in Antarctic bryozoans. Mar Environ Res. 129:68-75.

Hansen KO, Isaksson J, Bayer A, Johansen JA, Andersen JH, Hansen E. 2017.

Securamine derivatives from the Arctic bryozoan Securiflustra securifrons. J Nat Prod. 80(12):3276-3283.

Hansen KO, Isaksson J, Glomsaker E, Andersen JH, Hansen E. 2018. Ponasterone A and F, ecdysteroids from the Arctic bryozoan Alcyonidium gelatinosum. Molecules. 23(6).

Kollár P, Rajchard J, Balounová Z, Pazourek J. 2014. Marine natural products: bryostatins in preclinical and clinical studies. Pharm Biol. 52(2):237-242.

Li G, Lou H-X. 2018. Strategies to diversify natural products for drug discovery. Med Res Rev. 38(4):1255-1294.

Ma Q, Davidson PM, Zhong Q. 2013. Antimicrobial properties of lauric arginate alone or in combination with essential oils in tryptic soy broth and $2 \%$ reduced fat milk. Int $\mathbf{J}$ Food Microbiol. 166(1):77-84.

Maltseva AL, Kotenko ON, Kutyumov VA, Matvienko DA, Shavarda AL, Winson MK, Ostrovsky AN. 2017. Novel brominated metabolites from bryozoa: a functional analysis. Nat Prod Res. 31(16):1840-1848.

Michael P, Hansen KO, Isaksson J, Andersen JH, Hansen E. 2017. A novel brominated alkaloid securidine A, isolated from the marine bryozoan Securiflustra securifrons. Molecules. 22(7).

Peters L, Konig GM, Terlau H, Wright AD. 2002. Four new bromotryptamine derivatives from the marine bryozoan Flustra foliacea. J Nat Prod. 65(11):1633-1637. Ryland JS. 2005. Bryozoa: an introductory overview.

Schmidt NW, Wong GCL. 2013. Antimicrobial peptides and induced membrane curvature: geometry, coordination chemistry, and molecular engineering. Curr opin solid st m. 17(4):151-163.

Schmitz FJ, Hollenbeak KH, Prasad RS. 1979. Marine natural products: cytotoxic spermidine derivatives from the soft coral Sinularia brongersmai. Tetrahedron Lett. 20(36):3387-3390.

Schreier S, Malheiros SVP, de Paula E. 2000. Surface active drugs: self-association and interaction with membranes and surfactants. Physicochemical and biological aspects. Biochim Biophys Acta. 1508(1):210-234.

Svenson J. 2013. MabCent: Arctic marine bioprospecting in Norway. Phytochem rev. 12(3):567-578.

Tadesse M, Tabudravu JN, Jaspars M, Strom MB, Hansen E, Andersen JH, Kristiansen PE, Haug T. 2011. The antibacterial ent-eusynstyelamide B and eusynstyelamides D, E, and F from the Arctic bryozoan Tegella cf. spitzbergensis. J Nat Prod. 74(4):837-841. Tian XR, Tang HF, Tian XL, Hu JJ, Huang LL, Gustafson KR. 2018. Review of bioactive secondary metabolites from marine bryozoans in the progress of new drugs discovery. Future Med Chem. 10(12):1497-1514.

Yu CM, Wright JL. 1995. Murrayanolide, an unusual C21 tetracyclic terpenoid lactone from the marine bryozoan Dendrobeania murrayana. J Nat Prod. 58(12):1978-1982. 
